\section{LESSON 85}

Postcards

Margins

Address

Reference and date

Message

The date could be typed at the left-hand margin two single lines below the reference, as in the fully blocked style.

The reverse side of a postcard is addressed like an envelope.

If you are using an Elite typewriter, make your own right-hand margin.

Postcard 1

PAPER: A6.

TARGET TIME: 8 minutes.
Very often, firms and other institutions find it quicker and cheaper to send short messages by means of a postcard. These may be pre-printed and need only to be addressed, or they may be blank cards to be typed in full. Postcards are cheaper to buy than paper and envelopes. The Post Office Guide should be consulted about maximum and minimum sizes. The exercises in this book are for A6 size postcards - a sheet of A4 paper folded into four.

When typing a postcard, use margins of at least $13 \mathrm{~mm}(1 / 2$ inch $)$ at each side.

Typed or printed across the top of the postcard, on the message side, is he name and address of the firm sending it.

Type the reference and date two single lines below the last line of the address as in the semi-blocked letter style, on the same line.

Type the main body of the postcard three single lines below the date line in single-line spacing with a blank line between paragraphs. The paragraphs can be blocked or indented. It is not necessary to use a salutation or a close.

Type this on a sheet of A6 paper and fill in the instructions. Keep it for reference.

\section{Turn up 4 single linero}

The Trendy Dress shop, The Arcade, Chichester, Sussex. SU4 $8 \mathrm{CH}$ Turn up 2 single lines. NSB/RP

Date as postmark

\section{Turn up 3 single lines.}

The new summer dress that you ordered on the first of last month is now ready and awaiting collection.

Leave a single line batween paragraphs.

Will you please note that our early closing day is Wednesday, when we close at 1.00 p.m.

Please bring your receipt, or this postcard, with you when you call for your garment.

Turn up 2 single lines.

Susan Bowers

Manageress

Margin

$13 \mathrm{~mm}$

$\left(\frac{1}{2}\right.$ inch)
Margin

$13 \mathrm{~mm}$

( $\frac{1}{2}$ inch)
Send the above postcard to: Miss Jane Wilson, 41 Apple Drive, Chichester. SU3 4AD

Use a sheet of $A 6$ paper as a postcard as you send this to:

From: Miss Susan Stone, 11 Green Lane, Altrincham. CHI 6AL Altrincham Hockey Club. Date as postmark You have been selected to play for the lst team, away from home on Saturday next. (Paragraph) The team will meet at $12.30 \mathrm{p} . \mathrm{m}$. at the Club House. (Paragraph) If you are unable to play please telephone the Match secretary as soon as possible. 